\title{
Ivy leaf (Hedera helix) for acute upper respiratory tract infections: an updated systematic review
}

\author{
Elizabeth Sierocinski ${ }^{1}$ (D) $\cdot$ Felix Holzinger ${ }^{2}$ (D) - Jean-François Chenot ${ }^{1}$ (D)
}

Received: 30 July 2020 / Accepted: 13 January 2021 / Published online: 1 February 2021

(C) The Author(s) 2021

\begin{abstract}
Purpose Acute cough due to viral upper respiratory tract infections (URTIs) and bronchitis is a common reason for patients to seek medical care. Non-antibiotic over-the-counter cough medications such as ivy leaf extract are frequently used but their efficacy is uncertain. Our purpose was to update our previous systematic review and evaluate the effectiveness and tolerability of ivy leaf in the treatment of acute URTIs in adult and pediatric populations.

Methods We searched MEDLINE, EMBASE, the Cochrane Library, and clinical trial registries from December 2009 to January 2020. Randomized controlled trials (RCTs), controlled clinical trials (CCTs), and observational studies (OSs) investigating ivy leaf mono- or combination preparations were included. Two independent reviewers assessed records for eligibility and risk of bias and performed data extraction.

Results Six RCTs, 1 CCT, and 4 OSs were identified. Since the publication of our previous review, the number of RCTs has increased. All studies concluded that ivy leaf extract is an effective and safe option for the treatment of cough due to URTIs and bronchitis. Three RCTs reported a more rapid reduction in cough severity and/or frequency under ivy leaf treatment. The clinical significance of these effects appears to be minimal. No serious adverse effects were reported. The overall quality of reporting was low and the risk of bias was high.

Conclusions Ivy leaf preparations are safe for use in cough due to acute URTIs and bronchitis. However, effects are minimal at best and of uncertain clinical importance.
\end{abstract}

Keywords Acute cough $\cdot$ Bronchitis $\cdot$ Ivy leaf extract $\cdot$ Hedera helix

\section{Introduction}

Acute cough is one of the most common reasons for an individual to seek physician care and to require sick leave from work or school $[1,2]$. Viral upper respiratory tract infections (URTIs) and acute bronchitis are the most common cause of acute cough [1] and are hallmarked by general malaise, low or no fever, sore throat, rhinitis, congestion, headache, muscle aches, and cough. Systemic symptoms

Elizabeth Sierocinski

elizabeth.sierocinski@med.uni-greifswald.de

1 Department of General Practice, Institute for Community Medicine, Universitätsmedizin Greifswald, Greifswald, Germany

2 Department of General Practice, Charite - Universitätsmedizin Berlin, Berlin, Germany typically recede after 2-3 days but cough may persist for several weeks [3].

Antibiotics for viral URTIs and bronchitis are ineffective and even harmful due to potential side effects as well as the contribution to the development of bacterial resistance [4]. Despite widespread knowledge of the associated risks, antibiotics are frequently prescribed to patients with URTIs and bronchitis [5]. To combat this issue and to assist physicians in the challenge of alleviating acute cough caused by viral illnesses, a strong evidence base regarding the efficacy and safety of non-antibiotic cough remedies in adults and children is needed.

Ivy leaf (Hedera helix) extract preparations are widely used over-the-counter, non-antibiotic cough remedies authorized by the European Medicines Agency [6-8]. Ivy leaf extract contains saponins which are believed to have expectorant properties [9]. In vitro studies of ivy mono-preparations show evidence of potential antispasmodic and bronchodilating activity, anti-inflammatory effects, and antitussive properties 
[9]. This review is an update of our systematic review published in 2011 which found that evidence for the efficacy of ivy leaf extract in acute cough was inconclusive due to lack of methodologically robust data [10]. The objective of this review was to identify and evaluate new data regarding the effectiveness and tolerability of ivy leaf in the symptomatic treatment of acute bronchitis associated with acute URTIs in children and adults.

\section{Methods}

Search methods We conducted a systematic literature search of MEDLINE, EMBASE, and the Cochrane Library from December 2009 until January 2020. Search strategies are available as supplementary material. We hand-searched the bibliographies of retrieved publications and manufacturer websites. Additionally, we searched the World Health Organization International Clinical Trials Registry Platform (WHO ICTR), ClinicalTrials.gov, the European Union Clinical Trials Register (EU CTR), and European Network of Centres for Pharmacoepidemiology and Pharmacovigilance (ENCePP) for ongoing and completed trials and observational studies. We included records in English, German, French, Spanish, and Polish.

Study selection Randomized controlled trials (RCTs), controlled clinical trials (CCTs), and non-controlled observational studies (OSs) were included.

Participants The target participants were adults and children with upper respiratory tract infections (URTIs) and bronchitis. Studies including other acute diseases such as chronic obstructive pulmonary disease (COPD) and asthma were only included if the majority of subjects had URTIs or bronchitis.

Interventions Herbal expectorants in any dosage containing ivy leaf extract either as a single agent or in combination with other herbal agents were targeted.

Outcomes We targeted clinical outcomes (e.g., morbidity, health-related quality of life); surrogate values (spirometric parameters); physical findings (auscultation); symptom (cough); and tolerability assessment by physicians or patients.

Data extraction and management Two independent reviewers (JFC and ES) screened records for inclusion and extracted data using a predesigned template. Disagreements were resolved by consensus.

Risk of bias assessment Two independent reviewers used the Cochrane Risk-of-Bias tools for Randomized Trials (RoB-2) and Non-randomized Studies of Interventions (ROBINS-I) to assess the outcome- and study-level level risk of bias of RCTs and CCTs/OSs, respectively $[11,12]$. Disagreements were resolved by consensus. Financial conflicts of interest and publication bias were also assessed [13].

Data synthesis and subgroup analysis Included studies were categorized by study design. For controlled studies, the following subgroup comparisons were planned: ivy leaf extract vs. placebo; ivy leaf extract vs. conventional therapy; comparison of different formulations of ivy leaf extract. ROB figures were generated using robvis software [14]. All other figures were generated using drawi.io.

The review protocol is published on PROSPERO (CRD42019141405).

\section{Results}

Description of studies We identified 387 potentially relevant records, including 11 trial protocols (Online Resource 1). Four protocols corresponded to studies included in our review and 7 lacked published results. One full-text article was excluded due to a language barrier [15] and 11 studies were included (Fig. 1) [15].

The studies included 3592 patients (Tables 1 and 2). Two RCTs did not differentiate between acute and chronic cough, although chronic lung diseases such as COPD and asthma were excluded [16, 17]. One RCT included only patients with recurrent acute URTIs ( $\geq 6$ /year) [18]. Three OSs included subjects with pneumonia [19] and chronic respiratory diseases $[20,21]$.

Risk of bias Of the RCTs, 2 were found to be at low risk, 3 at high risk, and 1 with some concerns for bias (Fig. 2a). Sources of bias included inadequately described randomization, lack of blinding (2 single-blind [16, 17], 1 open-label [18]), incomplete baseline data, subjective outcome measurements, and selective reporting of results. Of the non-randomized studies, 4 were found to be at serious and 1 at critical risk of bias (Fig. 2b). Sources of bias included uncontrolled confounders, subjective and unblinded measurement of outcomes, and selective reporting of results. Several RCTs and OSs explicitly allowed concomitant medication for the target condition (expectorants [18] and antipyretics [18, 22-24] or antibiotics $[18,19,25])$.

Overall, most studies were found to be at risk of selection bias due to inadequate descriptions of populations screened for eligibility and selection processes.

Financial conflicts of interest Six studies declared sponsorship [19, 20, 22-24] or were commissioned by [20] pharmaceutical companies. Five studies did not report funding sources. Of these, 3 were affiliated with the manufacturer of the 


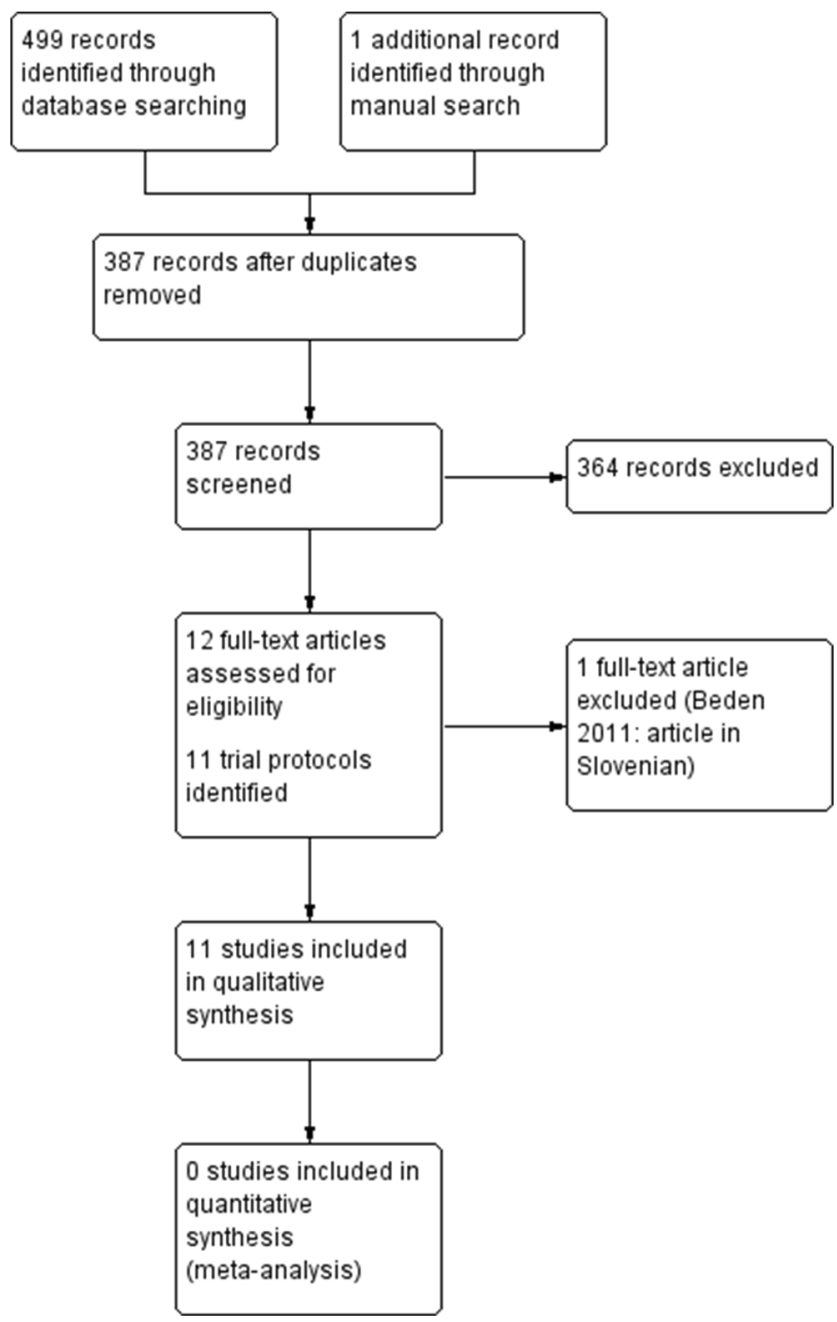

Fig. 1 Study selection process

investigational product $[16,17,21]$ and 2 received medications from pharmaceutical companies but did not report affiliations $[18,26]$.

\section{Effects of interventions}

Ivy versus placebo Two double-blinded RCTs compared an ivy mono-preparation to placebo in 390 adults over 7 days $[23,24]$ (Table 2). Cough severity was measured by the Bronchitis Severity Scale (BSS) and Visual Analog Scale (VAS) and cough frequency by the Verbal Category Descriptive (VCD) scale (Fig. 3). Statistically significant differences in BSS, VAS, and VCD improvement favoring ivy treatment were reported by treatment day 3 .

Two single-blinded RCTs compared an ivy/marsh-mallow/ London rocket preparation to placebo in 370 adults and children over 7 days $[16,17]$. Physician-measured improvements in cough, congestion, sore throat/chest discomfort, fatigue/ weakness, fever, and body ache were reported. A higher percentage of moderate and complete symptom resolution in the intervention group compared to the control was reported.

Ivy versus other therapies One open-label RCT compared an ivy/thyme preparation to standard care, defined as warm alkaline mineral water, an antipyretic (paracetamol), decongestant drops, and a local antibiotic (fusafungin) in 54 children for 7 10 days [18]. Outcomes included the proportion of patients with wet cough and congestion, number of daily coughing fits, fever, and laboratory markers of inflammation. The difference in coughing fits was statistically significant at treatment days 3-4 (approximately 12 vs. 18 fits/day in treatment versus standard care groups, respectively), but not at subsequent follow-up.

The CCT compared an ivy/marsh-mallow/London rocket preparation to a poly-herbal comparator in 60 adults and children over 15 days [26]. Cough intensity, throat soreness, congestion, sputum production and viscosity, and shortness of breath were measured using an unspecified method. Coughrelated quality of life (QoL) was measured via the Leicester Cough Questionnaire (LCQ, Online Resource 2). A statistically significant decrease in all symptoms in the investigational group compared to baseline was reported.

Different ivy formulations A double-blinded, randomized noninferiority trial including 590 adults and children compared two ivy mono-preparations for 6-8 days [22]. Outcomes included BSS improvement, physician- and patient-/parent-rated efficacy and tolerability, and percent of patients able to return to school or work. The BSS decreased in the entire study population, with a nonsignificant difference between groups.

Observational studies The four prospective OSs investigated ivy mono-preparations in 2128 patients, $86.2 \%$ of which were children [19-21, 25]. Three OSs included concomitant antibiotics and cold medications (e.g., decongestants, nasal sprays) in analyses [19, 21, 25]. Of these, one OS included a subgroup analyses; patients who did not receive antibiotics showed slightly higher percentages of clinical worsening [19].

Adverse events and tolerability All studies recorded data on adverse events, most of which were gastrointestinal [20-22, 24-26]. Two mild unspecified allergic reactions were reported [25] and one isolated skin reaction was possibly related to an ivy mono-preparation [20]. Patient-reported tolerability was reported as good or very good overall [20-22, 24, 25].

Heterogeneity of studies Four studies measured cough severity using the BSS [22-25] and 1 modified the BSS to include wheezing instead of sputum [19] (Fig. 3). The heterogeneity of study designs, inclusion criteria, and treatments precluded meta-analysis. 


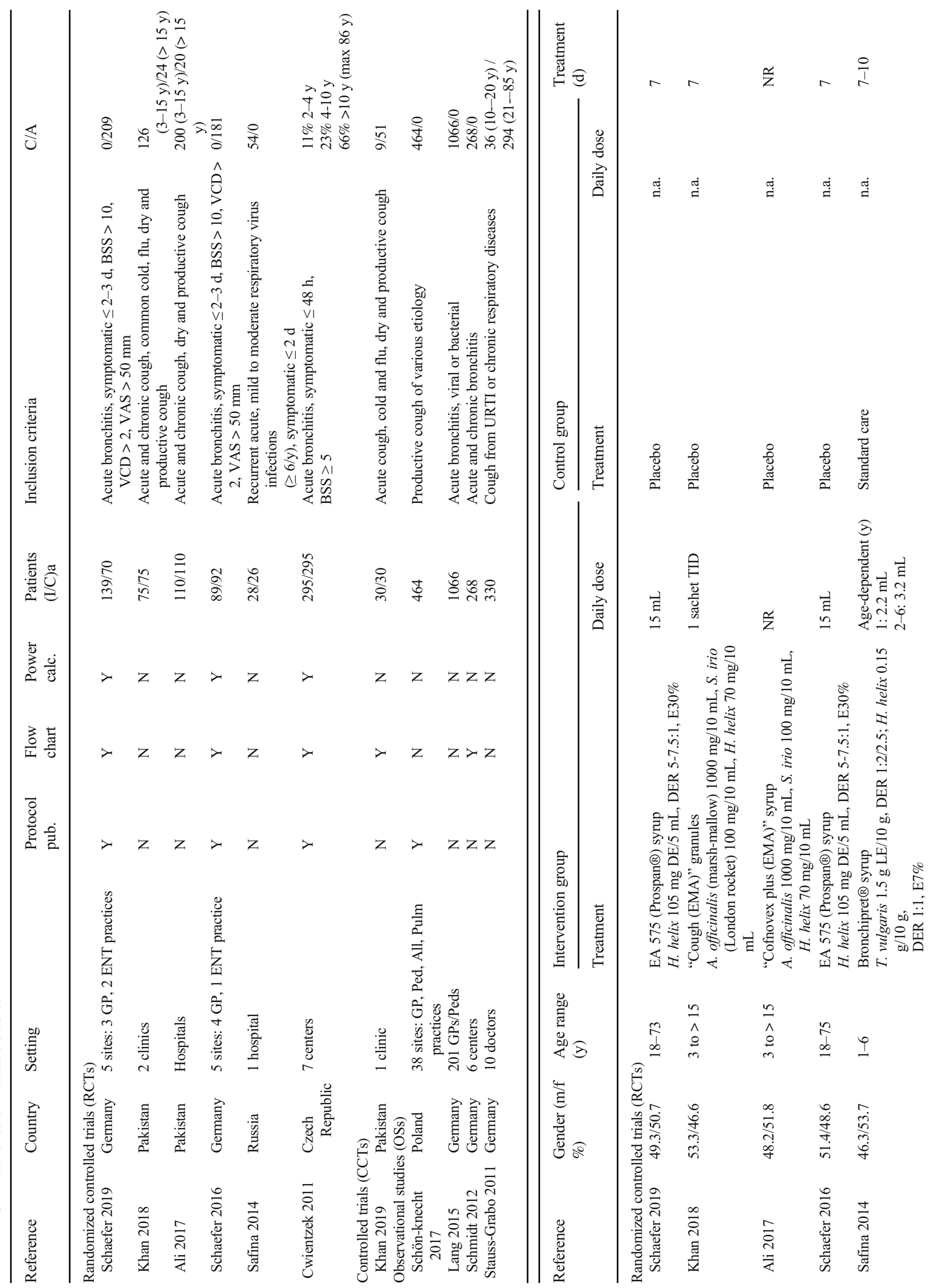




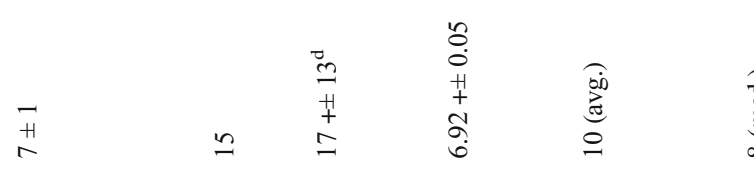

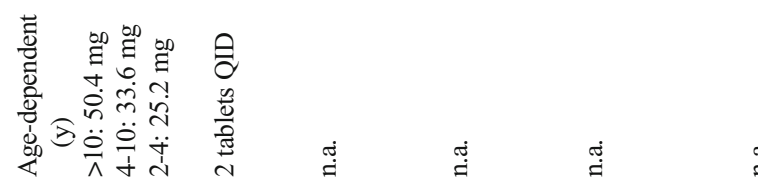

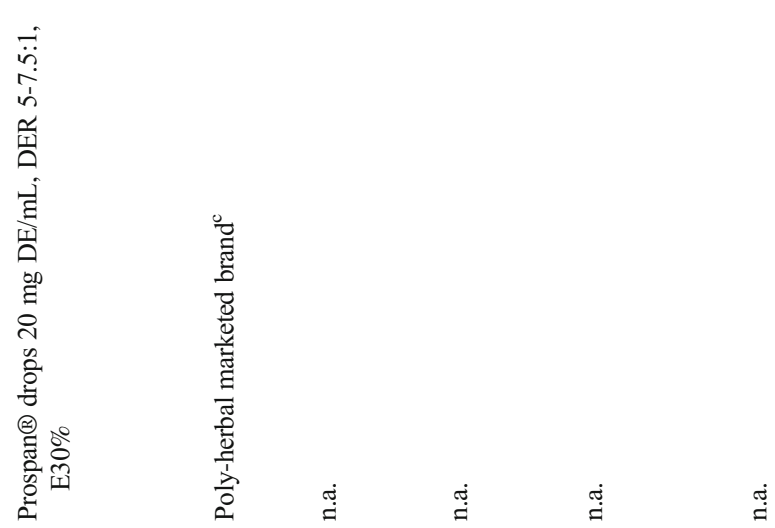

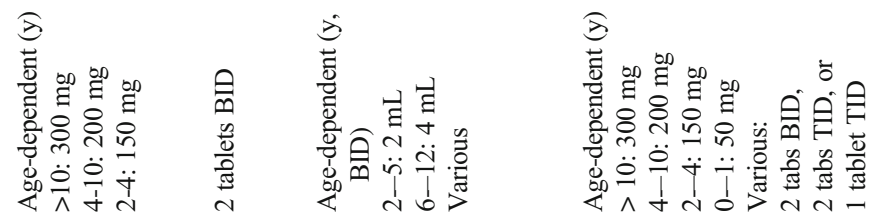

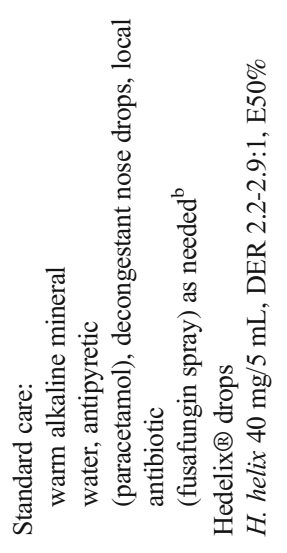

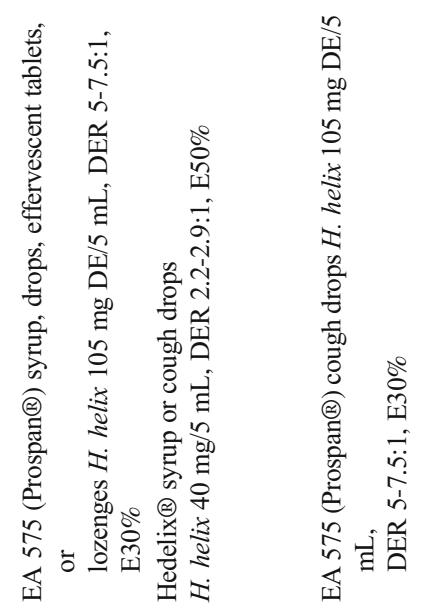


Table 2 Summary of results of included studies

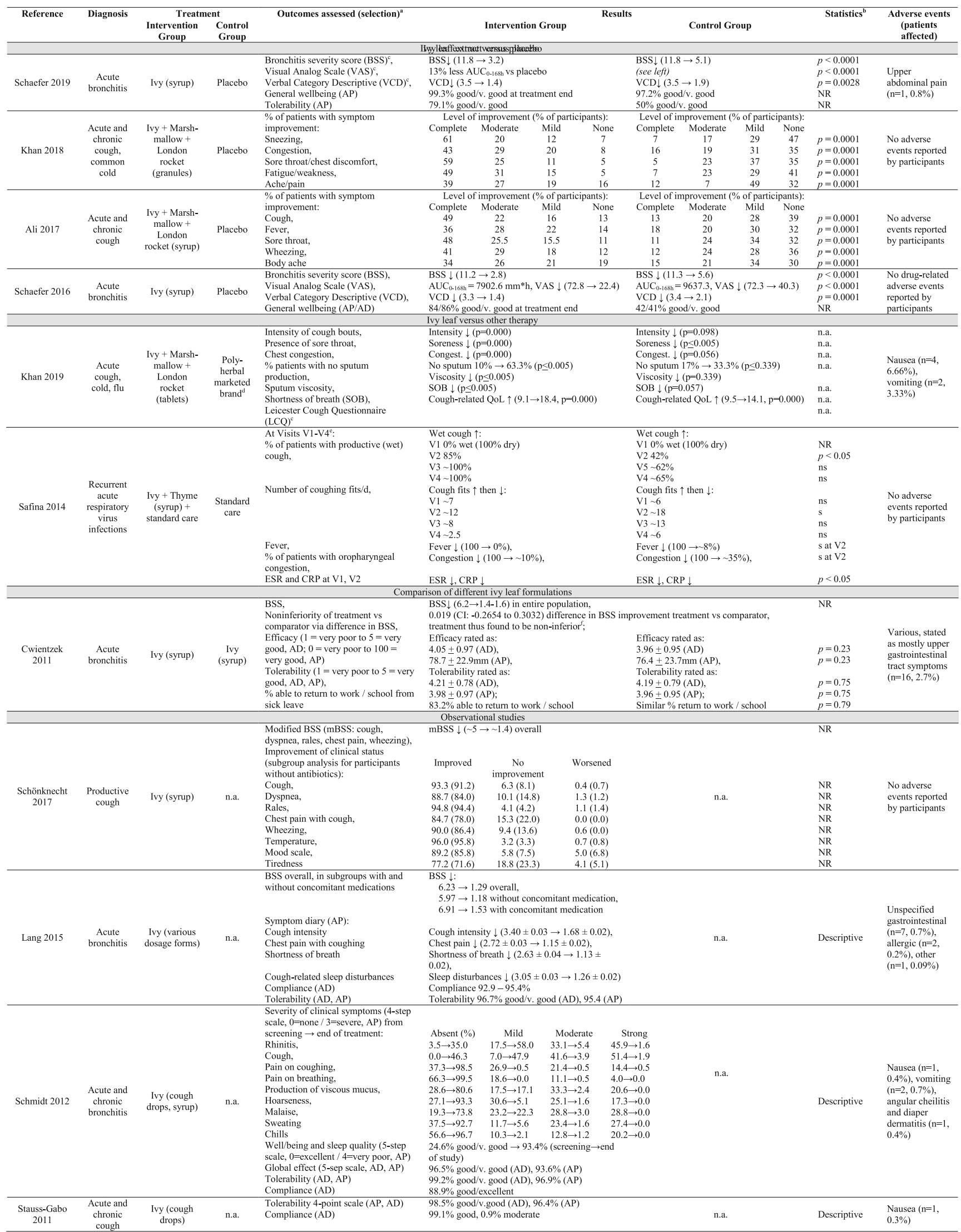


$d$ days, $n$.a. not applicable, $N R$ not reported, $n s$ not statistically significant, $s$ statistically significant, $v$. very, $A b x$ antibiotics, $A U C_{0-168 h}$ area under the curve over 7 days, $A D$ assessment by doctor, $A P$ assessment by patient or caregiver in the case of children, $C I$ confidence interval, $Q o L$ quality of life, ${ }^{\mathrm{a}}$ only outcome parameters reported in a manner allowing for comparison between groups are listed (RCT/CCT), for OS: selected relevant outcomes, ${ }^{\mathrm{b}}$ if reported: $p$ value for intervention compared to control. For OS: $p$ value for baseline compared to after treatment, ${ }^{\mathrm{c}}$ for detailed context, explanation (where applicable), validation and minimal clinically significant difference of this and other outcome measures, see Online Resource 2, ${ }^{\mathrm{d}}$ Combination of: Morus nigra, liquorice dry extract, Adhatoda vasica dry extract, Ocimum basilicum dry extract, menthol, anisi oil, eucalyptus oil, pine oil, cubeb oil, cinnamon oil. ${ }^{\mathrm{e}}$ V1 took place on day of study entry, V2 after 3-4 days, V3 after 7-10 days, and V4 after 14-17 days. ${ }^{\mathrm{f}}$ The difference in BSS improvement was used to determine noninferiority of treatment vs. comparator (noninferiority margin $=-0.6208$ ); “ $~ "$ indicates that the value was extrapolated from a figure and no exact value was reported in the study

\section{Discussion}

Summary of main results We identified 6 RCTs, 1 CCT, and 4 OSs. Compared to our previous review, the number of RCTs investigating ivy preparations in acute URTIs and bronchitis has increased. All studies concluded that ivy leaf extract is safe. Three RCTs reported a more rapid reduction in cough severity and/or frequency under ivy treatment compared to placebo or standard care. Study heterogeneity precluded quantitative synthesis and meta-analysis. With the exception of two studies, the overall quality of reporting was low and risk of bias was high.

Effectiveness Measuring the efficacy of therapies for acute URTIs and bronchitis is challenging as symptoms typically

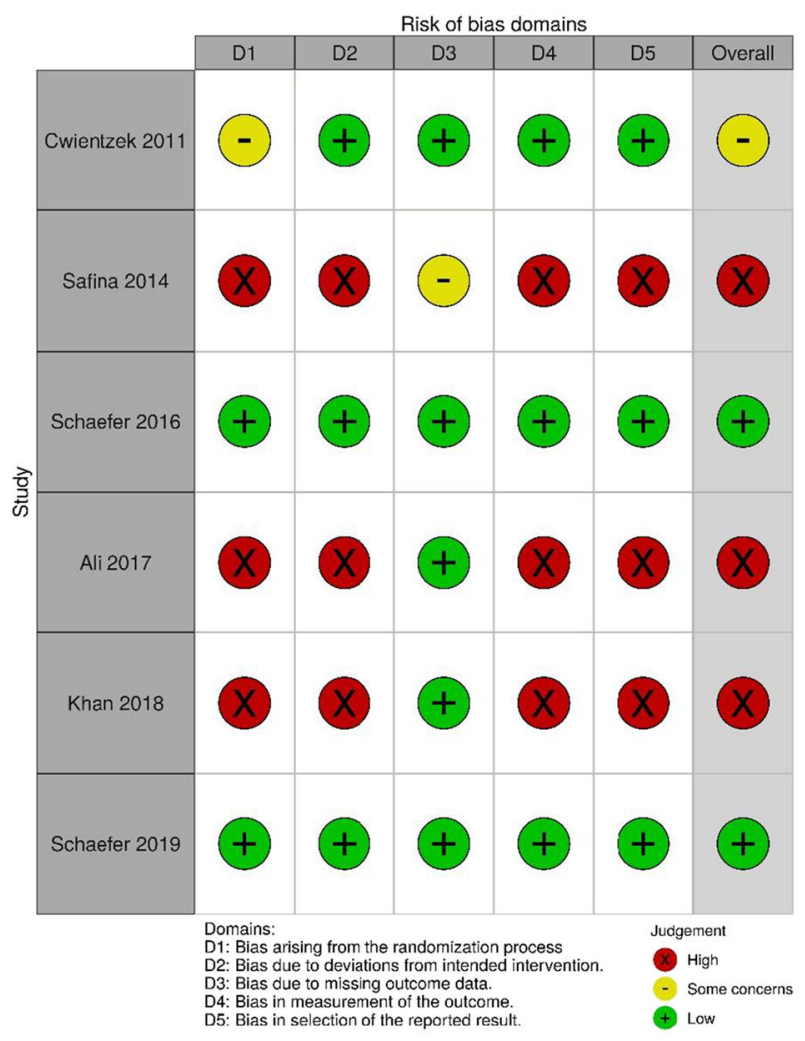

a recede after 5-11 days, regardless of intervention [27]. Correspondingly, the clinical condition of participants improved in both treatment and comparison groups. Values for the minimal clinically important difference (MID), or the smallest change perceived by patients as important, are available for two of the tools used to measure cough severity in the studies in our review: $17 \mathrm{~mm}$ for the Visual Analog Scale (VAS) and 2 points for the Leicester Cough Questionnaire (LCQ, Online Resource 2) [28]. One RCT reported VAS differences of 11.1 and $17.9 \mathrm{~mm}$ between treatment and placebo groups at day 3 and at the end of the treatment period, respectively [23]. Based on the MID, the effect of ivy leaf treatment at 3 days was likely too small to be perceived as important by patients but the difference after 7 days was potentially clinically noticeable. The CCT reported an LCQ difference of

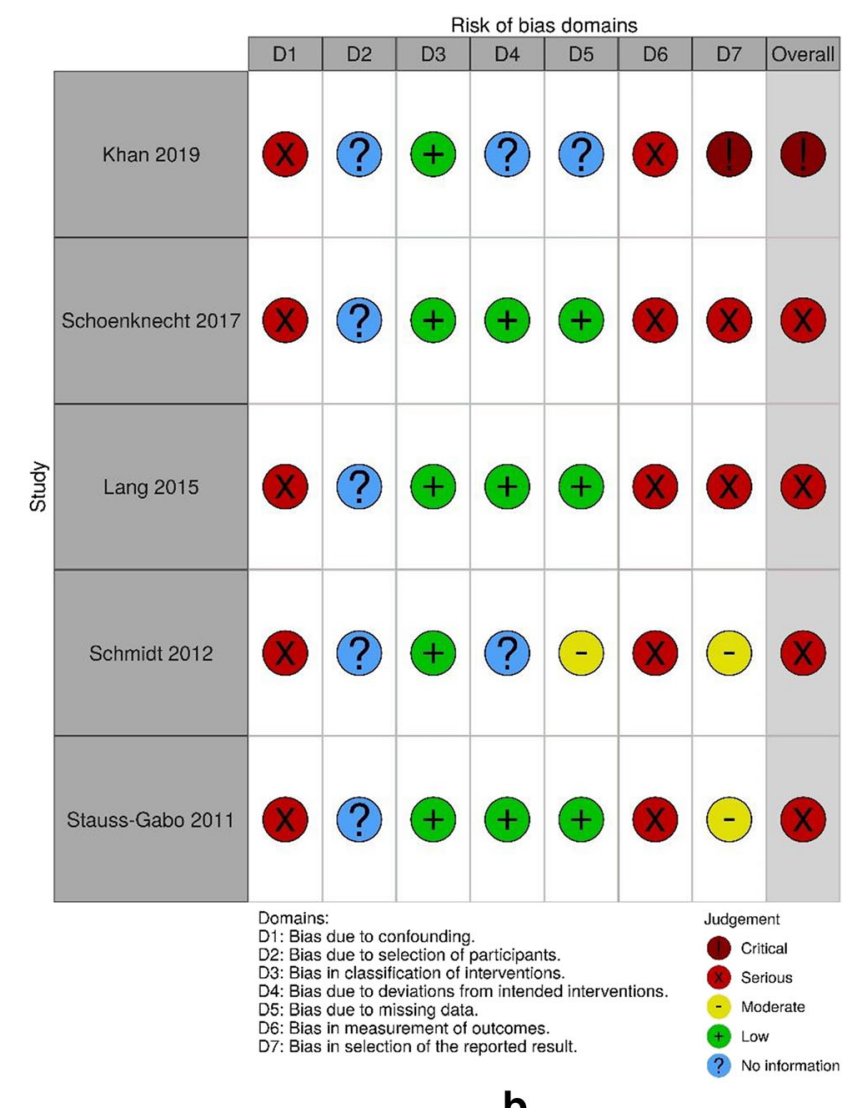

Fig. 2 Cochrane risk of bias assessment for a) RCTs, based on five domains and ranging from low to high; b) non-randomized studies, based on seven domains and ranging from low to critical 
Fig. 3 Five heterogeneous studies reporting cough severity via the Bronchitis Severity Scale (BSS) in four cases and a modified BSS (mBSS, wheezing instead of sputum assessed) in one case. Intervention groups are represented by a diamond shape and placebo groups by a circle. A combined circle and diamond shape depicts the BSS for a noninferiority study which combined data for the intervention and comparator groups. The populations of nonrandomized studies are represented by squares; text within the squares indicates which comedication was allowed

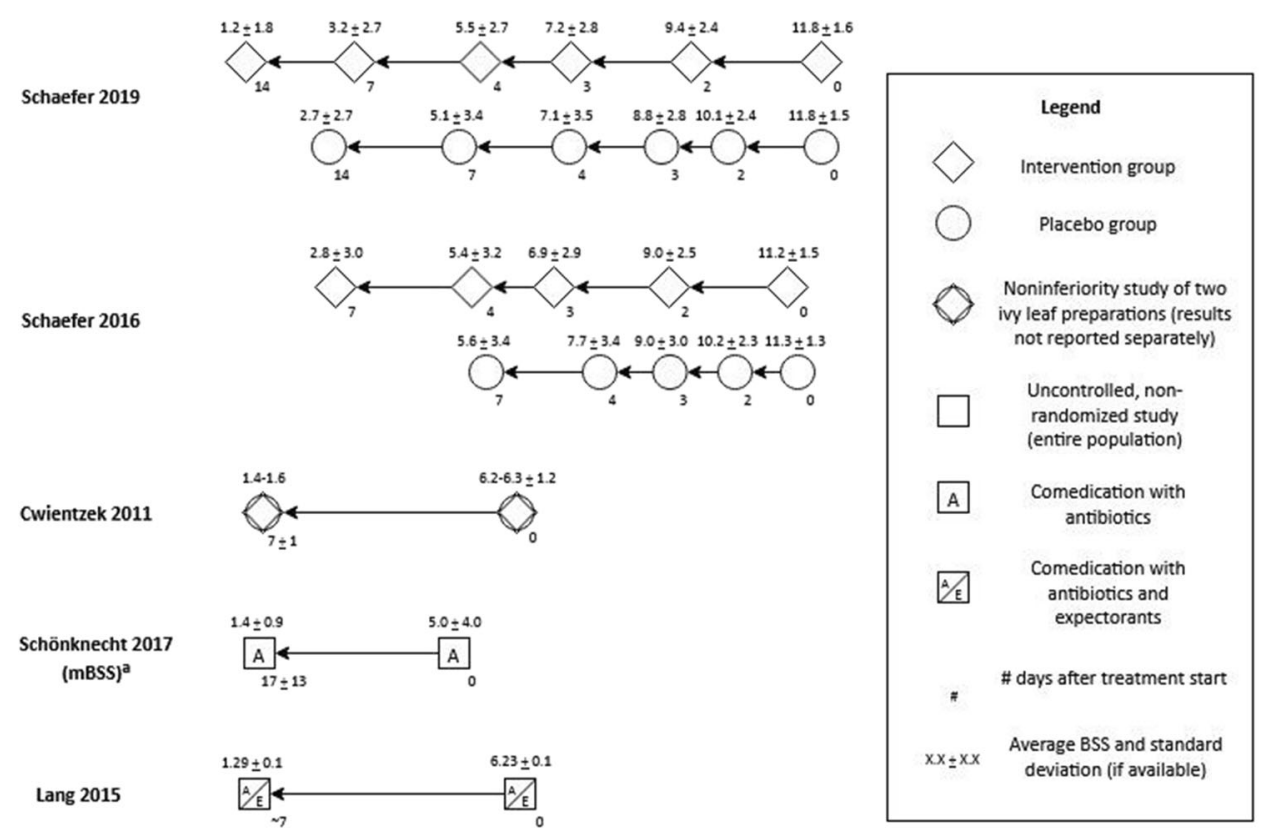

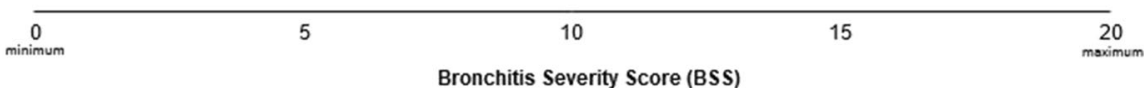

4.3 at the end of the treatment period, indicating a potentially clinically noticeable difference [26].

Half of the RCTs investigated combination preparations which included other active herbal ingredients in addition to ivy leaf extract [16-18]. It is possible that effects described by these studies may be due to the other herbal ingredients or synergy with ivy. The noninferiority trial comparing two different mono-preparations of ivy leaf extract established the equivalency of the test products [22] but did not provide evidence for efficacy. Regarding OSs, conclusions regarding efficacy cannot be drawn due to study design; however, these studies suggest safety and tolerability of ivy preparations.

Applicability of evidence Inclusion criteria and population selection varied. Three studies drew participants from specialist (ear-nose-throat, allergology, pulmonology) practices [19, 23, 24], 1 from family medicine and pediatric practices [25], and 7 did not specify source population [16-18, 20-22, 26]. One RCT only included patients with recurrent respiratory tract infections [18]. Specialist referrals often occur in complicated cases or when diagnostic and/or therapeutic options are exhausted in primary care [29], and recurrent infections may indicate more severe underlying disease [30]. This decreases the applicability of these results to our target population of patients with uncomplicated URTIs and bronchitis.

Completeness of evidence We identified 11 trial protocols, 7 without published results. Of these, 6 were RCTs completed 2 or more years prior to our search. Results are typically published within 2 years of trial completion and up to $50 \%$ of results are never published [31]. We interpret this as evidence of publication bias and postulate that data regarding treatment efficacy is missing from the literature. Given that positive, statistically significant results are more likely to be published than negative or nonsignificant results [32], the unpublished results may describe a lack of efficacy.

Quality of evidence Two included studies were at low risk of bias per the Cochrane assessment. This is a minimal improvement to our previous systematic review, in which 1 of 10 included studies was of robust quality per the Jadad scale [10]. All but 1 of the remaining studies were at high or critical risk of bias. The standard of reporting was poor. Half of the RCTs and all OSs measured cough severity subjectively using unblinded outcome assessors. Comedication was expressly allowed in 5 studies [18, 21, 23-25] and not specified in 3 $[16,17,26]$, limiting the validity of conclusions.

Nine studies were at risk of bias due to financial conflict of interest resulting from manufacturer sponsorship or affiliation. Studies funded by drug companies are 4 times more likely to report favorable outcomes and are at higher risk of publication bias and bias due to inappropriate comparisons [33, 34]. The results of the industry-funded studies included in this review are thus less likely to be generalizable [34]. 
Results in context Four included studies [21, 23-25] also appear in a review of the efficacy of ivy monopreparation EA 575 in acute and chronic cough [35]. Contrary to our conclusions, this review concludes that EA 575 is efficacious in treating cough. Possible explanations for this difference include the lack of assessment of quality, risk of bias, and clinical significance, as well as bias resulting from financial conflicts of interest [35]. Compared to our 2011 systematic review on this topic [10], the newly published studies are, with few exceptions, of a similarly low methodological quality and continue to show potential bias due to funding by manufacturers.

The majority of adverse events reported by the included studies were of mild to moderate severity and gastrointestinal in nature, corresponding to other publications citing gastrointestinal complaints as the main side effect of ivy preparations [9]. Rare serious adverse events such as anaphylaxis have been reported in the literature [36, 37], but were not reported by the studies in this review.

Strengths and limitations Our comprehensive search of major medical databases and supplementary manual search identified studies from multiple countries. Despite manual searching, studies in journals not listed in MEDLINE or EMBASE may have been missed. We had to exclude one study that may have been eligible for inclusion due to a language barrier (Slovenian).

\section{Authors' conclusions}

Implications for practice Ivy preparations may lead to a marginal reduction in cough symptoms compared to the naturally self-limiting course of URTIs. However, the clinical significance of these effects appears to be minimal. Serious adverse reactions are unlikely.

Implications for research Given the minimal treatment effects reported in the current literature and the natural course of URTIs and bronchitis, it seems unlikely that high-quality, large-scale studies will establish clinically important effects.

Supplementary Information The online version contains supplementary material available at https://doi.org/10.1007/s00228-021-03090-4.

Author contribution ES drafted the protocol/search terms; ES and FH implemented database searches. ES and JFC screened results, extracted data, and assessed RoB independently. ES drafted the manuscript, tables, and figures; FH and JFC approved the submitted draft.

Funding Open Access funding enabled and organized by Projekt DEAL.
Data availability Complete search strategies are available in Online Resource 3.

\section{Declarations}

Conflict of interest FH reports co-authorship of an evidence-based clinical guideline on the management of cough published by the German College of General Practitioners and Family Physicians. JFC and ES have no conflicts of interest to disclose.

Code availability Not applicable.

Open Access This article is licensed under a Creative Commons Attribution 4.0 International License, which permits use, sharing, adaptation, distribution and reproduction in any medium or format, as long as you give appropriate credit to the original author(s) and the source, provide a link to the Creative Commons licence, and indicate if changes were made. The images or other third party material in this article are included in the article's Creative Commons licence, unless indicated otherwise in a credit line to the material. If material is not included in the article's Creative Commons licence and your intended use is not permitted by statutory regulation or exceeds the permitted use, you will need to obtain permission directly from the copyright holder. To view a copy of this licence, visit http://creativecommons.org/licenses/by/4.0/.

\section{References}

1. Holzinger F, Beck S, Dini L, Stoter C, Heintze C (2014) The diagnosis and treatment of acute cough in adults. Dtsch Arztebl Int 111(20):356-363. https://doi.org/10.3238/arztebl.2014.0356

2. Fendrick AM, Monto AS, Nightengale B, Sarnes M (2003) The economic burden of non-influenza-related viral respiratory tract infection in the United States. Arch Intern Med 163(4):487-494. https://doi.org/10.1001/archinte.163.4.487

3. Ebell MH, Lundgren J, Youngpairoj S (2013) How long does a cough last? Comparing patients' expectations with data from a systematic review of the literature. Ann Fam Med 11(1):5-13. https:// doi.org/10.1370/afm.1430

4. Costelloe C, Metcalfe C, Lovering A, Mant D, Hay AD (2010) Effect of antibiotic prescribing in primary care on antimicrobial resistance in individual patients: systematic review and meta-analysis. BMJ 340:c2096. https://doi.org/10.1136/bmj.c2096

5. Smith SM, Fahey T, Smucny J, Becker LA (2017) Antibiotics for acute bronchitis. Cochrane Database Syst Rev 6:Cd000245. https:// doi.org/10.1002/14651858.CD000245.pub4

6. Du Y, Wolf IK, Zhuang W, Bodemann S, Knoss W, Knopf H (2014) Use of herbal medicinal products among children and adolescents in Germany. BMC Complement Altern Med 14(218):218. https://doi.org/10.1186/1472-6882-14-218

7. Italia S, Batscheider A, Heinrich J, Wenig C, Bauer CP, Koletzko S, Lehmann I, Herbarth O, von Berg A, Berdel D, Hoffmann B, Schaaf B, Wolfenstetter SB (2012) Utilization and costs of conventional and alternative pharmaceuticals in children: results from the German GINIplus and LISAplus birth cohort studies. Pharmacoepidemiol Drug Saf 21(10):1102-1111. https://doi.org/ $10.1002 /$ pds. 3323

8. Schwabe U, Paffrath D, Ludwig W-D, Klauber J (2019) Arzneiverordnungs-Report 2019. Springer Verlag GmbH Deutschland. https://doi.org/10.1007/978-3-662-59046-1

9. European Medicines Agency Committee on Herbal Medicinal Products (HMPC) (2018) Assessment report on Hedera helix L., folium 
10. Holzinger F, Chenot JF (2011) Systematic review of clinical trials assessing the effectiveness of ivy leaf (hedera helix) for acute upper respiratory tract infections. Evid Based Complement Alternat Med 2011(382789):382789-382789. https://doi.org/10.1155/2011/ 382789

11. Sterne JA, Hernan MA, Reeves BC, Savovic J, Berkman ND, Viswanathan M, Henry D, Altman DG, Ansari MT, Boutron I, Carpenter JR, Chan AW, Churchill R, Deeks JJ, Hrobjartsson A, Kirkham J, Juni P, Loke YK, Pigott TD, Ramsay CR, Regidor D, Rothstein HR, Sandhu L, Santaguida PL, Schunemann HJ, Shea B, Shrier I, Tugwell P, Turner L, Valentine JC, Waddington H, Waters E, Wells GA, Whiting PF, Higgins JP (2016) ROBINS-I: a tool for assessing risk of bias in non-randomised studies of interventions. BMJ 355:i4919. https://doi.org/10.1136/bmj.i4919

12. Sterne JAC, Savovic J, Page MJ, Elbers RG, Blencowe NS, Boutron I, Cates CJ, Cheng HY, Corbett MS, Eldridge SM, Emberson JR, Hernan MA, Hopewell S, Hrobjartsson A, Junqueira DR, Juni P, Kirkham JJ, Lasserson T, Li T, McAleenan A, Reeves BC, Shepperd S, Shrier I, Stewart LA, Tilling K, White IR, Whiting PF, Higgins JPT (2019) RoB 2: a revised tool for assessing risk of bias in randomised trials. BMJ 366:14898. https://doi.org/10.1136/bmj.14898

13. Higgins J, Thomas J, Chandler J, Cumpston M, Li T, Page M, Welch Ve (2019) Cochrane Handbook for Systematic Reviews of Interventions version 6.0 (updated July 2019)

14. McGuinness LA (2019) Robvis: an R package and web application for visualising risk-of-bias assessments

15. Beden AB, Perko J, Tercelj R, Kreft S (2011) Treatment of acute respiratory infections in Slovenian children with ivy leaf extract syrup (Potek zdravljenja akutne okuzbe dihal pri Slovenskih otrocih s sirupom, ki vsebuje izvlecek listov brsljana.). Zdr Vestn 80(4): 276-284

16. Khan MF, Akram M, Akhter N, Mukhtiar M, Zahid R, Khan FS, Daniyal M, Tahir IM, Ahmed K, Sharif A, Kausar S, Shah SMA, Usmanghani K (2018) The evaluation of efficacy and safety of Cough (EMA) granules used for upper respiratory disorders. Pak J Pharm Sci 31(6):2617-2622

17. Ali Z, Daniyal M, Adhia MK, Alam A, Sarfaraz B, Sattar A, Usmanghani K (2017) To evaluate the efficacy and safety of CofNovex plus (EMA) syrup. Pak J Pharm Sci 30(2(Suppl)):591596

18. Safina A (2014) Treatment of young children with recurrent acute respiratory tract infections with a herbal combination of thyme herb and ivy leaf. Zeitschrift für Phytotherapie 35(6):262-267. https:// doi.org/10.1055/s-0034-1395797

19. Schonknecht K, Fal AM, Mastalerz-Migas A, Joachimiak M, Doniec Z (2017) Efficacy of dry extract of ivy leaves in the treatment of productive cough. Wiad Lek 70(6 pt 1):1026-1033

20. Schmidt M, Thomsen M, Schmidt U (2012) Suitability of ivy extract for the treatment of paediatric cough. Phytother Res 26(12): 1942-1947. https://doi.org/10.1002/ptr.4671

21. Stauss-Grabo M, Atiye S, Warnke A, Wedemeyer RS, Donath F, Blume HH (2011) Observational study on the tolerability and safety of film-coated tablets containing ivy extract (Prospan(R) Cough Tablets) in the treatment of colds accompanied by coughing. Phytomedicine 18(6):433-436. https://doi.org/10.1016/j.phymed. 2010.11.009

22. Cwientzek U, Ottillinger B, Arenberger P (2011) Acute bronchitis therapy with ivy leaves extracts in a two-arm study. A double-blind, randomised study vs. an other ivy leaves extract. Phytomedicine 18(13):1105-1109. https://doi.org/10.1016/j.phymed.2011.06.014

23. Schaefer A, Kehr MS, Giannetti BM, Bulitta M, Staiger C (2016) A randomized, controlled, double-blind, multi-center trial to evaluate the efficacy and safety of a liquid containing ivy leaves dry extract
(EA 575((R))) vs. placebo in the treatment of adults with acute cough. Pharmazie 71(9):504-509. https://doi.org/10.1691/ph. 2016.6712

24. Schaefer A, Ludwig F, Giannetti BM, Bulitta M, Wacker A (2019) Efficacy of two dosing schemes of a liquid containing ivy leaves dry extract EA 575 versus placebo in the treatment of acute bronchitis in adults. ERJ Open Res 5(4):00019-02019. https://doi.org/ 10.1183/23120541.00019-2019

25. Lang C, Staiger C, Wegener T (2015) Efeu in der pädiatrischen Praxis (Efeu in der padiatrischen Praxis.). Zeitschrift für Phytotherapie 36(05):192-196. https://doi.org/10.1055/s-0041105237

26. Khan M, Rehman H, Naveed S, Zaidi SF, Ayaz S, Owais A, Usmanghani K (2019) Chewable cough tablets with improved palatability: a comparative phase II clinical trial. Pak J Pharm Sci 32(1(Supplementary)):339-343

27. Mitra A, Hannay D, Kapur A, Baxter G (2011) The natural history of acute upper respiratory tract infections in children. Prim Health Care Res Dev 12(4):329-334. https://doi.org/10.1017/ S1463423611000193

28. Lee KK, Matos S, Evans DH, White P, Pavord ID, Birring SS (2013) A longitudinal assessment of acute cough. Am J Respir Crit Care Med 187(9):991-997. https://doi.org/10.1164/rccm. 201209-1686OC

29. Akbari A, Mayhew A, Al-Alawi MA, Grimshaw J, Winkens R, Glidewell E, Pritchard C, Thomas R, Fraser C (2008) Interventions to improve outpatient referrals from primary care to secondary care. Cochrane Database Syst Rev 4:CD005471. https:// doi.org/10.1002/14651858.CD005471.pub2

30. Jesenak M, Ciljakova M, Rennerova Z, Babusikova E, Banovcin P (2011) Recurrent respiratory infections in children-definition, diagnostic approach, treatment and prevention. In: Martin-Loeches I (ed) Bronchitis, pp 119-148. https://doi.org/10.5772/19422

31. Ross JS, Mocanu M, Lampropulos JF, Tse T, Krumholz HM (2013) Time to publication among completed clinical trials. JAMA Intern Med 173(9):825-828. https://doi.org/10.1001/ jamainternmed.2013.136

32. Dwan K, Gamble C, Williamson PR, Kirkham JJ (2013) Systematic review of the empirical evidence of study publication bias and outcome reporting bias - an updated review. PLoS One 8(7):e66844. https://doi.org/10.1371/journal.pone.0066844

33. Lexchin J, Bero LA, Djulbegovic B, Clark O (2003) Pharmaceutical industry sponsorship and research outcome and quality: systematic review. BMJ 326(7400):1167-1170. https:// doi.org/10.1136/bmj.326.7400.1167

34. Savovic J, Akl EA, Hrobjartsson A (2018) Financial conflicts of interest in clinical research. Intensive Care Med 44(10):1767-1769. https://doi.org/10.1007/s00134-018-5333-3

35. Lang C, Rottger-Luer P, Staiger C (2015) A valuable option for the treatment of respiratory diseases: review on the clinical evidence of the ivy leaves dry extract EA 575(R). Planta Med 81(12-13):968974. https://doi.org/10.1055/s-0035-1545879

36. Morfin-Maciel BM, Rosas-Alvarado A, Velazquez-Samano G (2012) Anaphylaxis due to ingestion of ivy syrup (Hedera hElix). Report of two cases. Rev Alerg Mex 59(1):31-36

37. Pokladnikova J, Meyboom RH, Meincke R, Niedrig D, Russmann S (2016) Allergy-like immediate reactions with herbal medicines: a retrospective study using data from VigiBase(R). Drug Saf 39(5): 455-464. https://doi.org/10.1007/s40264-016-0401-5

Publisher's note Springer Nature remains neutral with regard to jurisdictional claims in published maps and institutional affiliations. 